\title{
Health Consequences Associated with Being Overweight or Obese: A Swedish Population- Based Study of 85-Year-Olds
}

\author{
Huan-Ji Dong, Mitra Unosson, Ewa Wressle and Jan Marcusson
}

\section{Linköping University Post Print}

N.B.: When citing this work, cite the original article.

This is the authors' version of the following article:

Huan-Ji Dong, Mitra Unosson, Ewa Wressle and Jan Marcusson, Health Consequences Associated with Being Overweight or Obese: A Swedish Population-Based Study of 85-YearOlds, 2012, Journal of The American Geriatrics Society, (60), 2, 243-250.

which has been published in final form at:

http://dx.doi.org/10.1111/j.1532-5415.2011.03827.x

Copyright: Wiley-Blackwell http://eu.wiley.com/WileyCDA/Brand/id-35.html

Postprint available at: Linköping University Electronic Press http://urn.kb.se/resolve?urn=urn:nbn:se:liu:diva-76197 


\title{
Health Consequences Associated with being Overweight or Obese: A Swedish Population-based study of 85-year-olds
}

\author{
Huan-Ji Dong, $\mathrm{MD}^{*}$, Mitra Unosson, $\mathrm{PhD}^{\dagger}$, Ewa Wressle, $\mathrm{PhD}^{*}$, \\ and Jan Marcusson, $\mathrm{MD}, \mathrm{PhD}^{*}$
}

*Division of Geriatrics, Department of Clinical and Experimental Medicine, Faculty of Health Sciences, Linköping University, Department of Geriatric Medicine, County Council of Östergötland, Linköping, Sweden

†Department of Social and Welfare Studies, Linköping University, Norrköping, Sweden

Corresponding author:

Huan-Ji Dong

Dept of Geriatric Medicine

Linköping University Hospital

SE-581 85 Linköping, Sweden

Phone: +46101038051

Fax: +46101034141

E-mail: huanji.dong@liu.se 


\section{ABSTRACT}

OBJECTIVES: To determine whether being overweight or obese is associated with significant health outcomes in an 85-year-old population.

DESIGN: A cross-sectional population-based study.

SETTING: The participants lived in Linköping municipality, Sweden.

PARTICIPANTS: Three hundred thirty-eight people born in 1922 were identified using the local authority's register.

MEASUREMENTS: Data related to socio-demographics, Health-Related Quality of Life (HRQoL), assistance use, and the presence of diseases were collected by a postal questionnaire. Anthropometry and functioning status were assessed during home and geriatric clinic visits. Diseases were double-checked in the electronic medical records and information about health service consumption was provided by the local health care register.

RESULTS: Overweight (Body Mass Index (BMI): 25-29.9 $\mathrm{kg} / \mathrm{m}^{2}$ ) and obese (BMI $\geq 30$ $\mathrm{kg} / \mathrm{m}^{2}$ ) subjects perceived more difficulty performing instrumental activities of daily living (IADL) and had more co-morbidity than their normal weight counterparts (BMI: 18.5-24.9 $\mathrm{kg} / \mathrm{m}^{2}$ ). However, their overall HRQoL and health service cost did not differ from normal weight subjects. After controlling for socio-demographic factors, being overweight did not influence IADL or any co-morbidity, but obese subjects were more likely to perceive increased difficulty in performing outdoor activities (OR: 2.1, 95\% CI: 1.1-4) and cleaning (OR: 2.2, 95\% CI: 1.2-4.2) than normal weight counterparts. Although obesity was also associated with multi-morbidity (OR: 3, 95\% CI: 1.2-8), the health service cost of each case of multi-morbidity ( $\mathrm{n}=251$ ) was highest in subjects with normal weight and nearly three times as much as in obese subjects (ratio: $2.9,95 \% \mathrm{CI}: 1.1-8.1$ ). 
CONCLUSION: For 85-year-olds, being obese, as opposed to overweight, is associated with self-reported activity limitations and co-morbidities. Overweight elderly living in their own homes in this population had similar well-being to those with normal weight.

KEY WORDS: health consequences, overweight, obesity, 85-year-olds 


\section{INTRODUCTION}

Research suggests that being overweight or obese is related to negative health consequences, as bodyweight influences health outcomes (1). Gerontology researchers have widely studied the association of being overweight and obese with different aspects of health, such as disease burden (2, 3), functional limitations (4), poorer Health-related Quality of Life (HRQoL) (5), and higher consumption of health services $(6,7)$. However, many of these studies rely on data from younger elderly or mixed-age groups. The knowledge about very old overweight or obese people is incomplete. Unlike younger adults, controversy exists about the harmful aspects of being overweight or obese among older people (8). Earlier studies have demonstrated a lower total or disease-specific mortality in obese subjects, but a significant association between obesity and the adverse effects from co-morbidity $(8,9)$. Little is known whether these findings are the same for very old people. Furthermore, elderly overweight people represent a large percentage of the ageing population although few studies examine how weight issues affect the health of very old people. Today, the population aged 80 and over is growing even faster than the population aged 65 and over (10). Clearly, this trend means that it is going to be very important to investigate to what extent elevated Body Mass Index (BMI) affects health consequences in very old people. Based on the previous findings in younger old adults and mixed-age group populations, we hypothesized that being overweight and being obese are associated with negative health consequences that include decreased HRQoL, decreased functional status, increased co-morbidity, and increased use of health services. This study describes health consequences in an 85-year-old population sample and determines whether being overweight or being obese is associated with the significant health outcomes.

\section{METHODS}




\section{Subjects}

All subjects were enrolled in the Elderly in Linköping Screening Assessment (ELSA-85) project, a prospective population-based study of 85-year-olds living in Linköping municipality, Sweden (11). The cohort for this project was based on the local authority register for individuals born in 1922 and living in Linköping municipality in 2007 (n=650). Two months after these individuals' $85^{\text {th }}$ birthday, they received a postal questionnaire and an invitation letter to participate at the beginning of every month. The letter contained information about the study and the option to participate in each phase (postal questionnaire, home visit, and geriatric clinic visit). If the individuals had limited autonomy, such as mental incapacity or physical limitations, their close relatives could act as their proxy, accepting the invitation and helping complete the questionnaire. A reminder was sent by post if no response to the letter of invitation was received within two weeks.

\section{Data collection}

Data was gathered related to several aspects of socio-demographics: gender, marital status (married/widowed, divorced or never married), cohabitating, type of housing (ordinary housing/sheltered accommodation or nursing home), level of education (primary school/secondary grammar school/university), and socio-economic status (SES). SES refers to the subjects' previous working status and was classified into the following categories: low (blue collar), intermediate (white collar), and high (self-employed or academic profession) (12).

Data was also collected related to several aspects of anthropometry. Body weight was measured using an electronic balance scale (SECA model 708, Germany) with subjects lightly clothed and shoeless. Height was measured in a standing position to the nearest $0.1 \mathrm{~cm}$. BMI was calculated (body weight $(\mathrm{kg}) /$ height $(\mathrm{m})^{2}$ and classified according to the criteria 
developed by the WHO (13): <18.5 = underweight; 18.5-24.9= normal range; $25.0-29.9=$ overweight; $\geq 30.0=$ obesity.

Activities of daily living (ADLs) included personal activities of daily living (PADL) and instrumental activities of daily living (IADL). PADL consisted of four basic personal-care functions: bathing or showering, dressing and undressing, toileting, and eating. Each category was scored as 0 (managed without help), 1 (needs some help), or 2 (needs much help). IADL was examined using the Instrumental Activity Measure (IAM). A four-level ordinal scale was used to assess difficulty (none, little, great, or impossible) performing eight activities: mobility outdoors, preparing simple meals, cooking, using public transportation, small-scale shopping, large-scale shopping, cleaning (e.g., making a bed, daily tidying up, vacuuming, etc.), and washing (various tasks for managing laundry) (14). Good construct validity has been reported in a previous study $(14,15)$ and good internal consistency (Cronbach alpha of 0.89) was demonstrated in the present study.

To assess functional mobility, the Timed Up and Go (TUG) test was used (16). The test times how long it takes a subject to stand up from an armchair, walk three meters, walk back to the chair, and sit down (16). If accomplishing this task requires more than 14 seconds, a person is at a high risk for falls.

Assistive technology (AT) was divided into two types: 1) mobility technology including the use of wheelchair, walker, or crutch and 2) personal care technology including the use of vertically adjustable bed, bath/shower technology, adapted toilet, portable toilet, or gripper (17). Eye glasses and hearing aids were not included in the present study. In addition to informal help (family/relatives), four formal services were investigated: transportation services, personal alarms, community assistance, and meal delivery. 
Health-related Quality of Life (HRQoL) was assessed using the EQ-5D questionnaire. Value sets for the five dimensions (mobility, self-care, usual activities, pain/discomfort, and anxiety/depression) in EQ-5D were converted to a single summary index value, range -0.594 to 1 . This index value was generated by means of the time trade-off method (18). A standard visual analogue scale (VAS) was also used for the individual's rating of current health state, ranging from 0 (worst imaginable health state) to 100 (best imaginable health state). Both the index value and VAS were used to elicit the valuations for health status $(19,20)$.

Co-morbidity was determined using the subjects' self-reporting and double-checked in the documents of patients' case reports. The criteria of the $10^{\text {th }}$ version of the International Classification of Diseases (ICD-10) was used to classify the diseases. Presence of chronic disease was registered if the disease fulfilled one or more of the following criteria: permanently present; caused by an irreversible pathological condition; or requiring rehabilitation or a long period of care. A predetermined list was made for common chronic diseases (prevalence $\geq 3 \%$ in the population). Multi-morbidity, defined as the presence of two or more chronic diseases, proved to be of great importance for disability or mortality (21).

Health service consumption data - the use and cost of health services during the preceding 12 months - were sorted and collected. Health services were categorized into services received in primary care centers and services received in hospitals. Primary care center visits included the primary care center visits and home visits from caregivers employed by a primary care center. Hospital visits included outpatient department visits, emergency department contacts, and hospital admissions. The financial costs were also divided into medication costs and costs for biochemical tests, radiology examinations, and physician consultations. The patients with multi-morbidity consumed relatively more health services, so we analyzed the medical costs for the elderly who exhibited multi-morbidity. 


\section{Procedure}

To fulfill all the information above, a questionnaire including social-demographics, EQ-5D, assistance uses, and queries about chronic diseases was used as an initial approach to the target population. After the participants consented to the next stage of the study, ADLs was evaluated during a home visit. Anthropometry and the assessment of functional mobility were completed in the geriatric clinic visit. Patients' case reports were reviewed by our research team - a research nurse collected medical histories from the electronic documents and a doctor completed the data registration by reviewing the records written in patients' case reports. Health service consumption data were retrieved from the local health care register.

\section{Statistical analyses}

Data are presented as means with standard deviation (SD) for variables with normal distribution and medians with interquartile range (IQR) for non-Gaussian distribution. The exception is the health service cost (Swedish crown), which is normalized by log transformation before analysis and is reported as geometric means with $95 \%$ confidence intervals $(\mathrm{CI})$.

Comparisons of values in categorical variables were made using the Chi-test (Fisher's exact test where appropriate). One-way ANOVA (Bonferroni method for post hoc test) was used to analyze continuous data with normal distribution and Kruskal-Wallis test (Mann-Whitney U test with Bonferroni method for post hoc test) was used to analyze interval data. A p-value of below 0.05 was regarded as significant. A reduced p-value $<0.017$ was used for MannWhitney U test, which served as a post hoc test to control for the risk of mass-significance (22). Pearson's correlation was performed between BMI as a continuous variable and the time required performing the TUG test. Ordinal or binary logistic regression examined the contributions of BMI (categorical and continuous) with IADL (a 4-level ordinal scale of 
perception of increased difficulty: none, little, great, and impossible) and co-morbidity (disease $=1$ and no disease $=0$ ). These associations were adjusted for socio-demographic factors (gender, co-residence, type of housing, education level, and SES) and presented as odds ratios (ORs) and 95\% CI (22). Marital status was excluded due to its high collinearity and correlation with co-residence. All analysis was accomplished using the PASW 18 software (IBM SPSS Statistics, Chicago, IL, USA).

\section{Ethical considerations}

The local Ethical Committee approved the study (Dnr 141-06, Linköping) and written informed consent was obtained from all participants and/or their relatives. Throughout the study, all participants were informed that taking part in the project was voluntary and participation could be terminated at any time.

\section{RESULTS}

The response rate for the study invitation was $90 \%(586 / 650)$. The recruitment profile is summarized in Figure 1. In total, 496 (78\% of all alive subjects) completed the questionnaire; 380 (77\% of those who completed the questionnaire) received a home visit; 338 (89\% of those who accepted home visit) visited the geriatric clinic for anthropometry and mobility testing.

Figure 1 about here

\section{Characteristics of the participants, non-participants, and dropouts}

The mean BMI was $26 \pm 4.0$. Men had a lower mean BMI $(24.9 \pm 4.6)$ than women $(26.8 \pm$ 2.7), $\mathrm{p}<0.001]$. Nearly half of the participants were overweight $(156 / 338,46 \%)$ and approximately one-fifth were obese $(58 / 338,17 \%)$. A total of $48 \%(69 / 144)$ of men and $45 \%$ 
(87/194) of women were overweight, and 8\% (11/144) of men and 24\% (47/194) of women were obese. Only five subjects $(5 / 338,1.5 \%)$ were underweight. The major demographic characteristics were female gender $(194 / 338,57 \%)$, living alone $(188 / 338,56 \%)$, residing in an ordinary house $(311 / 338,92 \%)$, primary school education $(230 / 338,68 \%)$, and low SES (blue collar) $(168 / 338,50 \%)$. As there were few underweight participants $(n=5)$, this underweight group was not included in later analyses.

A higher proportion of non-participants $(35 / 154,23 \%)$ than participants $(27 / 338,8 \%)$ lived in sheltered accommodation/nursing home $(\mathrm{p}<0.001)$ and there was no gender difference between non-participants and participants. After the completing the questionnaire, more women $(113 / 307,37 \%)$ than men $(45 / 189,24 \%, p=0.003)$ dropped out. Still, more dropouts $(28 / 158,18 \%)$ than participants $(27 / 338,8 \%, p=0.001)$ lived in non-ordinary housing. Almost one-third of the dropouts $(50 / 158,31 \%)$ and less than one-fourth of the participants $(73 / 338,22 \%)$ had been admitted to a hospital at least once during $2007(\mathrm{p}=0.016)$, but no significant difference was evident in terms of total financial cost (participants to dropouts ratio $=0.6,95 \%$ CI: 0.4-1.1, $\mathrm{p}=0.082$ ). Other socio-demographic factors (marital status, coresidence, levels of education, and SES) distributed similarly in dropouts and participants.

\section{Functioning and HRQoL}

More obese subjects than normal weight and overweight subjects required assistive technology and formal services from the community or relatives (Table 1). By categorizing the types of services, significant differences between groups were found in the use of transportation services $(\mathrm{p}=0.003)$ and the use of personal alarms $(\mathrm{p}=0.001)$, which over half of the obese subjects and around $30 \%$ of the overweight or normal weight subjects used. Less than $30 \%$ of the subjects required community assistance (p>0.05) and only 20 subjects used meal delivery services $(\mathrm{p}>0.05)$. 
Very few subjects perceived limitations in PADL and no difference between groups was evident ( $>0.05)$. In each activity of the IADL, more than half of normal weight subjects perceived no difficulty, whereas the proportions of 'no difficulty' in the other two groups were substantially lower in mobility outdoors, public transportation use, small and large scale shopping, cleaning, and washing $(\mathrm{p}<0.05,0.01)$. Obese subjects performed significantly slowest in the mobility test among the three groups and $81 \%(41 / 58)$ had a high risk for falls ( $\geq 14 \mathrm{~s})$. In comparison, 57\% (68/119) of normal weight subjects and 63\% (98/156) of overweight subjects were at a high risk for falls $(\mathrm{p}=0.007)$.

In the HRQoL, the generated index value and self-rated health evaluated by VAS were similar between groups, although a larger proportion of overweight $(70 / 156,45 \%)$ and obese subjects $(34 / 58,61 \%)$ than normal weight subjects $(46 / 119,39 \%)$ perceived moderate-severe mobility problems $(\mathrm{p}<0.05)$. No significant difference between groups was found in other EQ-5D dimensions (self-care, usual activities, pain/discomfort, and anxiety/depression).

\section{Table 1 about here}

The ordinal logistic regression showed that obese subjects were more likely to perceive increased difficulty in all six activities, and overweight subjects were only more likely to have increased difficulty in 'small scale shopping' and 'washing' (Table 2). After adjusting for all socio-demographic factors, the association of obesity with increased difficulty in 'mobility outdoors' and 'cleaning' remained significant, although the magnitude of ORs decreased. However, the association between overweight and the perceptions of difficulty in 'small scale shopping' (OR: 1.4, 95 \% CI: 0.8-2.6) and 'washing' (OR: 1.4, 95 \% CI: 0.8-2.4) disappeared. When BMI was considered as a continuous category, no significant relationship with the activity limitation was observed (data not shown), but there was a significant correlation between BMI and time required to perform the TUG test $(r=0.197, \mathrm{p}<0.001)$. 


\section{Co-morbidity and health service consumption}

Overweight and obese subjects outnumbered subjects with normal weight in number of chronic diseases (median number: 3, 3, and 2, respectively). Nearly $90 \%$ of obese subjects (52/58) had multi-morbidity, while the prevalence was significantly lower in both the overweight group $(115 / 156,74 \%)$ and the normal weight group $(84 / 119,70 \%, \mathrm{p}=0.018)$. The most frequent morbidity was hypertension and three diseases showed significant difference between subjects with different BMI-categories (Figure 2).

\section{Figure 2 about here}

Binary logistic regression detected that urinary incontinence had a weak but still statistically significant association with obesity (after adjustment OR: 2.2, 95\% CI: 1.1-4.7) (Table 2). Diabetes as well as chronic heart failure had increased ORs (0.2 and 0.6 after adjustment, respectively). Conversely, hypertension lost the significance of association with obesity after adjustment (OR: 1.6, 95\% CI: 0.8-3.2). However, being overweight was not found to have a significant association with any co-morbidity. BMI as a continuous variable remained significant for associations with all the four co-morbidity (data not shown) and the presence of arrhythmia after adjustment (OR: 1.1, 95\% CI: 1-1.2).

\section{Table 2 about here}

Although some differences in morbidities were evident among the groups, no statistical significance was found in health service use except that the obese subjects had the highest frequency of home visits (Table 3). Neither medication nor other health care fees showed any difference between groups; however, by stratifying the multi-morbidity $(n=251)$, normal weight subjects exhibited the highest health service total cost of each case of multi-morbidity, 
nearly three times as much as in obese subjects (ratio: 2.9, 95\% CI: 1.1-8.1). The difference was mainly due to the fee excluding medication costs (ratio: $2.8,95 \%$ CI: 2.0-7.0).

\section{Table 3 about here}

\section{DISCUSSION}

The present results suggest that overweight or obese 85-year-olds perceived more difficulties in a variety of ADLs and had more co-morbidity than their normal weight counterparts, but they had neither poorer overall HRQoL nor more health service cost. For overweight subjects, the significant impacts on activity limitations and co-morbidity disappeared after controlling for socio-demographic factors. However, the associations between obesity and activity limitation as well as between obesity and co-morbidity (or multimorbidity) remained significant even after adjustment.

To define overweight and obesity, current guidelines suggest using the same cut-off values for BMI in the elderly as for younger adults. The mean BMI in the present study was higher than the criteria for normal weight, a discrepancy also found in another Swedish study (BMI: 25.4 $\pm 4.1, \mathrm{n}=95$ ) (23). Some studies, including a study that focused on the $80+$ age group, also showed a mean BMI above 25 (24-26). In the present study, the largest proportion of subjects was overweight $(156,46 \%)$ and obesity accounted for the fewest $(58,17 \%)$. This was somewhat different from the Newcastle cohort study in which the majority of 85-year-old elderly were normal weight $(383,51 \%)$ and very few were obese $(73,10 \%)(27)$. Ogden et al. (28) reported a prevalence of $17 \%$ obesity in non-Hispanic white elderly aged 80 and over, a prevalence lower than both younger old (35\%) and middle-aged groups (34\%). Moreover, of the obese subjects in the present study, a majority (46/58, 80\%) was under BMI 35 (class I obesity). This was inconsistent with other studies with larger population samples: an extreme high BMI (35 39.9 and $\geq 40$, class II and III obesity respectively) was least likely for very old 
survivors $(24,27,29)$. The low prevalence of obesity might be explained by the selective mortality for younger people $(30,31)$. In the present study, many of the survivors were overweight, a finding that agrees with evidence from those previous studies that overweight elderly had no greater risk of mortality than normal weight elderly $(29,32,33)$.

We addressed key questions about health and diseases, with a special focus on quantitative assessment of factors that could be affected by both nutritional status and the advanced age strategy. Since aging is a complex process and long life expectancy is also attributed to multiple factors, it is inappropriate to deduce the advantages or negative effects based on only one or a few apparent variability in comparison to younger-old adults.

\section{Characteristics of the participants, non-participants, and dropouts}

Type of housing seemed to be the most important socio-demographic factor that differed between our participants, dropouts, and non-participants. Individuals living in nursing sheltered accommodation or nursing home were more likely to decline the participation and refused the following stages. Meanwhile, more hospital admissions were found in the dropouts than the participants, but their financial costs showed little difference. As described in other population-based studies, non-participants can be frailer (34), or surprisingly enough, more healthy, but with a depressed mental state (35). Based on the characteristics of housing types and health service use, we believe that our non-participants may have been frail, sick, and have high mortality. Thus, our sample population represented the 'healthy elite' as most of them managed their daily life without institutional care.

\section{Functioning and HRQoL}

In IADL, the results derived from ordinal logistic regression indicated overweight subjects perceived increased difficulty in 'small-scale shopping' and 'washing', although the socio- 
demographic factors somewhat weakened the association and the statistical significance was lost after adjustment. As some other studies pointed out, socio-demographic factors could not be ruled out because home activities were related to gender, cohabitation, and other cultural factors (14). The activity limitations, which were more likely perceived by obese subjects, could be attributed to their mobility limitations. The mobility problem was further proved by the actual physical performance on the TUG test, and BMI as a continuous variable also showed the positive correlation with the time required to perform the TUG test. However, we observed that the overweight subjects as a whole performed as well as normal weight subjects and significantly better than obese subjects. This indicated that BMI within the overweight range did not decrease functional mobility for the very old subjects. The negative consequence did not absolutely occur until BMI reached the range of obesity.

Some studies with mixed-age groups demonstrated that obesity is associated with poorer HRQoL but inconsistent with overweight (5, 36-38). Physical functioning, an aspect of HRQoL, is more likely to be associated with obesity $(5,39)$. The present study also addressed the mobility problem, the only dimension in the EQ-5D indicating differences among groups. Surprisingly, the overall HRQoL - health index value and self-rated health - was not affected by high BMI, as very old people might have adapted to a decline in their health and functional performance as their age increased (40). In the present study, however, most the elderly had good functioning in PADL and some of their functional limitations might be supported by formal community service or informal family help. From this information, we infer that the difference in HRQoL diminished between subjects with different BMI-category.

\section{Co-morbidity and health service consumption}

The fact that the co-morbidity showed similar prevalence with other studies was not striking, but the results about 'not higher risk' in overweight and similar health service consumption in 
overweight and obese subjects should be taken into consideration. In the present study, overweight in comparison to normal weight was not significantly associated with any comorbidity. Unlike the younger elderly, obesity-related conditions become more common in the older elderly and even in normal weight older elderly (41). Thus, it is reasonable to assume that the likelihood of having certain chronic diseases was similar for normal weight or overweight elderly subjects.

Another notable finding is health service consumption. In younger age populations, overweight and obesity as a health care burden often results in greater health service use (42, 43 ) and higher costs $(6,44)$. In the present study, we found the only obese subjects used home visits more frequently. This appeared reasonable in connection to their poorer mobility. What is less clear is why normal weight subjects with multi-morbidity had higher health care costs than obese subjects. A longitudinal study may provide a deeper understanding because the total health care expenditure might include costs associated with last-year-of-life care.

This study has several weaknesses. First, only 52\% (338/650) of all eligible 85-year-old residents participated in the study, so generalizing (external validity) our findings is problematic. Our findings are somewhat similar to other gerontology research for very old people. In the Newcastle 85+ study, for example, 51\% (747/1453) of the possible participants completed both health assessments, including BMI measurements and review of medical records (27). We know that involving and retaining very old people is not easy even if the response rate is good (90\%). The voluntary sample can be biased due to the study procedure, as the study design unintentionally selected subjects who were of strong interest for the study. Thus, we maximized the sample information by checking the registered data. A large proportion of individuals living in sheltered accommodation and nursing homes were inevitably neglected. Hence our study may not be generalizable to a vulnerable old population. Second, we realized that the subjects' actual use of assistance could be overestimated because 
the elderly might receive 'overt support' with daily activities from their family, discouraging them from engaging in activities and increasing the risk of falling (45). Third, our study did not consider under-diagnosed diseases, such as hyperlipidemia (46) and male osteoporosis (47), diseases that often are missing in the patients' case reports due to lack of medical examination or no intention of treatment.

\section{CONCLUSION}

In conclusion, for the very old elderly, being overweight seemed not to have greater impact on health burden than being normal weight. Obesity was considerably related to several activity limitations and co-morbidities. Given these findings, we feel it is strongly supported that very old people living in their own homes (without institutional care) can have good well-being while maintaining a BMI level that indicates being overweight. For those with obesity, to achieve a lower BMI might improve the relevant negative health consequences, but not necessarily provide benefits for those with multi-morbidity, if it is true that health service costs were spent more by normal weight elderly with multi-morbidity than by obese elderly. On the other hand, receiving help to improve activity limitation, especially mobility restriction, is more realizable for obese elderly than BMI reduction. Our study also shows two urgent needs for further research: one is to address the health consequences of vulnerable very old overweight people or obese people living in sheltered accommodations and nursing homes; and to profoundly evaluate health service consumption for very old people with different nutritional status from a longitudinal perspective. 


\section{ACKNOWLEDGMENTS}

Conflict of Interest: no declaration.

This work was supported by grants from The Health Research Council of the South-East of Sweden, the County of Östergötland and the Janne Elgqvist Family Foundation.

Author Contributions: Dong HJ: retrieval of literature, analysis (design and performance) and interpretation of data, drafting of manuscript. Unosson M: study concept, interpretation of data, manuscript development. Wressle E: study concept and design, acquisition of subjects and data, manuscript development. Marcusson J: study concept and design, data interpretation, and completion of the first draft into final manuscript version. All of the authors read and approved the manuscript for publication.

Special thanks to statisticians Mats Fredriksson and Karl Wahlin (Linköping Academic Research Centre) for their statistical consultations and supports.

Sponsor's Role: None. 


\section{References}

1. Houston DK, Nicklas BJ, Zizza CA. Weighty concerns: The growing prevalence of obesity among older adults. J Am Diet Assoc 2009;109:1886-1895.

2. Must A, Spadano J, Coakley EH et al. The disease burden associated with overweight and obesity. JAMA 1999;282:1523-1529.

3. Pi-Sunyer FX. Medical hazards of obesity. Ann Intern Med 1993;119:655-660.

4. Jensen GL. Obesity and functional decline: Epidemiology and geriatric consequences. Clin Geriatr Med 2005;21:677-687.

5. Yan LL, Daviglus ML, Liu K et al. BMI and health-related quality of life in adults 65 years and older. Obes Res 2004;12:69-76.

6. Yang Z, Hall AG. The financial burden of overweight and obesity among elderly Americans: The dynamics of weight, longevity, and health care cost. Health Serv Res 2008;43:849-868.

7. Lakdawalla DN, Goldman DP, Shang B. The health and cost consequences of obesity among the future elderly. Health Aff 2005;24:W5R30-41.

8. Zamboni M, Mazzali G, Zoico E et al. Health consequences of obesity in the elderly: A review of four unresolved questions. Int J Obes 2005;29:1011-1029.

9. Allison DB, Faith MS, Heo M et al. Hypothesis concerning the U-shaped relation between body mass index and mortality. Am J Epidemiol 1997;146:339-349.

10. Kinsella K, He W. An aging world: 2008. Washington, DC: U.S. Census Bureau, 2009, International Population Reports, No. P95/09-1.

11. Nagga $\mathrm{K}$, Dong $\mathrm{HJ}$, Marcusson $\mathrm{J}$ et al. Health-related factors associated with hospitalization for old people: Comparisons of elderly aged 85 in a population cohort study. Arch Gerontol Geriatr, 2011 [on-line]. Available at http://www.sciencedirect.com/science/article/pii/S0167494311001075 Accessed Juni 2, 2011 
12. Dutton DB, Levine S. Socioeconomic status and health: Overview, methodological critique, and reformulation. In: Bunker JP, Gomby DS, Kehrer BH, eds. In pathways to health: The role of social factors. 1st Ed. California: Menlo Park, The Henry J Kaiser Family Foundation, 1989, pp 29-69.

13. Obesity: Preventing and managing the global epidemic. Report of a WHO consultation. World Health Organ Tech Rep Ser 2000;894:i-xii, 1-253.

14. Grimby G, Andren E, Daving Y et al. Dependence and perceived difficulty in daily activities in community-living stroke survivors 2 years after stroke: A study of instrumental structures. Stroke 1998;29:1843-1849.

15. Grimby G, Andren E, Holmgren E et al. Structure of a combination of functional independence measure and instrumental activity measure items in community-living persons: A study of individuals with cerebral palsy and spina bifida. Arch Phys Med Rehabil 1996;77:1109-1114.

16. Podsiadlo D, Richardson S. The timed "up \& go": A test of basic functional mobility for frail elderly persons. J Am Geriatr Soc 1991;39:142-148.

17. Lofqvist C, Nygren C, Szeman Z et al. Assistive devices among very old people in five European countries. Scand J Occup Ther 2005;12:181-192.

18. Dolan P. Modeling valuations for EuroQol health states. Med Care 1997;35:1095-1108.

19. Drummond MF, Sculpher M, Torrance G et al. Methods for the economic evaluation of health care programmes. 3rd Ed. Oxford: Oxford University Press, 2005.

20. Burstrom K, Johannesson M, Diderichsen F. Swedish population health-related quality of life results using the EQ-5D. Qual Life Res 2001;10:621-635.

21. Marengoni A, Winblad B, Karp A et al. Prevalence of chronic diseases and multimorbidity among the elderly population in Sweden. Am J Public Health 2008;98:11981200. 
22. Altman DG. Practical statistics for medical research. London: Chapman \& Hall, 1991.

23. von Heideken Wagert P, Gustavsson JM, Lundin-Olsson L et al. Health status in the oldest old. Age and sex differences in the Umeå 85+ study. Aging Clin Exp Res 2006;18:116126.

24. Perissinotto E, Pisent C, Sergi G et al. Anthropometric measurements in the elderly: Age and gender differences. Br J Nutr 2002;87:177-186.

25. Sanchez-Garcia S, Garcia-Pena C, Duque-Lopez MX et al. Anthropometric measures and nutritional status in a healthy elderly population. BMC Public Health 2007;7:2.

26. Santos JL, Albala C, Lera L et al. Anthropometric measurements in the elderly population of Santiago, Chile. Nutrition 2004;20:452-457.

27. Collerton J, Davies K, Jagger C et al. Health and disease in 85 year olds: Baseline findings from the Newcastle 85+ cohort study. BMJ 2009;339:b4904.

28. Ogden CL, Yanovski SZ, Carroll MD et al. The epidemiology of obesity. Gastroenterology 2007;132:2087-2102.

29. Stessman J, Jacobs JM, Ein-Mor E et al. Normal body mass index rather than obesity predicts greater mortality in elderly people: The Jerusalem longitudinal study. J Am Geriatr Soc 2009;57:2232-2238.

30. Tsigos C, Hainer V, Basdevant A et al. Management of obesity in adults: European clinical practice guidelines. Obes Facts 2008;1:106-116.

31. Seidell JC. Prevalence and time trends of obesity in Europe. J Endocrinol Invest 2002;25:816-822.

32. Kulminski AM, Arbeev KG, Kulminskaya IV et al. Body mass index and nine-year mortality in disabled and nondisabled older U.S. individuals. J Am Geriatr Soc 2008;56:105110. 
33. Lang IA, Llewellyn DJ, Alexander K et al. Obesity, physical function, and mortality in older adults. J Am Geriatr Soc 2008;56:1474-1478.

34. Rockwood K, Mitnitski A. Frailty in relation to the accumulation of deficits. J Gerontol A Biol Sci Med Sci 2007;62:722-727.

35. der Wiel AB, van Exel E, de Craen AJ et al. A high response is not essential to prevent selection bias: Results from the Leiden 85-plus study. J Clin Epidemiol 2002;55:1119-1125.

36. Sach TH, Barton GR, Doherty $M$ et al. The relationship between body mass index and health-related quality of life: Comparing the EQ-5D, EuroQol VAS and SF-6D. Int J Obes 2007;31:189-196.

37. Kostka T, Bogus K. Independent contribution of overweight/obesity and physical inactivity to lower health-related quality of life in community-dwelling older subjects. $\mathrm{Z}$ Gerontol Geriatr 2007;40:43-51.

38. Lopez-Garcia E, Banegas Banegas JR, Gutierrez-Fisac JL et al. Relation between body weight and health-related quality of life among the elderly in Spain. Int J Obes Relat Metab Disord 2003;27:701-709.

39. Blane D, Netuveli G, Montgomery SM. Quality of life, health and physiological status and change at older ages. Soc Sci Med 2008;66:1579-1587.

40. Leinonen R, Heikkinen E, Jylha M. Predictors of decline in self-assessments of health among older people--a 5-year longitudinal study. Soc Sci Med 2001;52:1329-1341.

41. Chapman IM. Obesity paradox during aging. Interdiscip Top Gerontol 2010;37:20-36.

42. Leon-Munoz LM, Guallar-Castillon P, Lopez Garcia E et al. Relationship of BMI, waist circumference, and weight change with use of health services by older adults. Obes Res 2005;13:1398-1404.

43. Fontaine KR, Bartlett SJ. Access and use of medical care among obese persons. Obes Res 2000;8:403-406. 
44. Thompson D, Wolf AM. The medical-care cost burden of obesity. Obes Rev 2001;2:189197.

45. Yeom HA, Fleury J, Keller C. Risk factors for mobility limitation in community-dwelling older adults: A social ecological perspective. Geriatr Nurs 2008;29:133-140.

46. Shanmugasundaram M, Rough SJ, Alpert JS. Dyslipidemia in the elderly: Should it be treated? Clin Cardiol 2010;33:4-9.

47. Rocchietti March M, Pisani D, Aliberti G. Male osteoporosis. Minerva Endocrinol 2009;34:325-332. 
Table 1. Comparisons regarding assistance use, ADLs, mobility function, and overall HRQoL among 85-year-old people with normal weight, overweight, or obesity.

\begin{tabular}{|c|c|c|c|c|}
\hline & $\begin{array}{c}\text { Normal } \\
\text { weight n }(\%)\end{array}$ & $\begin{array}{c}\text { Overweight } \\
\text { n }(\%)\end{array}$ & $\begin{array}{l}\text { Obesity } \\
\text { n (\%) }\end{array}$ & p-value \\
\hline \multicolumn{5}{|l|}{ Assistance } \\
\hline Mobility AT use & $48(40.3)$ & $70(44.9)$ & $41(70.7)$ & $<0.001$ \\
\hline Personal care AT use & $37(31.1)$ & $65(41.7)$ & $31(53.4)$ & 0.014 \\
\hline Formal service use & $48(40.3)$ & $67(42.9)$ & $39(68.4)$ & 0.001 \\
\hline Informal service use & $73(61.3)$ & $112(71.8)$ & $38(82.8)$ & 0.011 \\
\hline PADL & & & & $0.225^{*}$ \\
\hline Manage all items & $105(88.2)$ & $131(84)$ & $47(81)$ & \\
\hline 1 limitation & $10(8.4)$ & $10(6.4)$ & $5(8.6)$ & \\
\hline$>=2$ limitations & $4(3.4)$ & $15(9.6)$ & $6(10.3)$ & \\
\hline \multicolumn{5}{|l|}{ IADL, no difficulty in IAM } \\
\hline Mobility outdoors & $78(65.5)$ & $88(56.4)$ & $22(37.9)$ & 0.002 \\
\hline Simple meal & $101(84.9)$ & $134(85.9)$ & $46(79.3)$ & 0.49 \\
\hline Cooking & $89(74.8)$ & $117(75)$ & $37(63.8)$ & 0.223 \\
\hline Public transportation & $82(68.9)$ & $80(51.3)$ & $22(37.9)$ & $<0.001$ \\
\hline Small scale shopping & $95(79.8)$ & $106(67.9)$ & $35(60.3)$ & 0.015 \\
\hline Large scale shopping & $80(67.2)$ & $95(60.9)$ & $26(44.8)$ & 0.016 \\
\hline Cleaning & $64(53.8)$ & $72(46.2)$ & $16(27.6)$ & 0.002 \\
\hline Washing & $85(71.4)$ & $91(58.3)$ & $29(50)$ & 0.012 \\
\hline Mobility function (second). Mean \pm & $16.2 \pm 6.3$ & $17.3 \pm 7.5$ & $20 \pm 8$ & $0.006^{\dagger}[\mathrm{abc}]$ \\
\hline SD, assessed by TUG test & & & & $0.004^{\dagger}[\mathrm{ac}]$ \\
\hline
\end{tabular}


Overall HRQoL, assessed by EQ-5D

Health index value (range -0.594 1), $0.77 \pm 0.2 \quad 0.72 \pm 0.25 \quad 0.72 \pm 0.17 \quad 0.105^{\dagger}$

Mean \pm SD

$\begin{array}{llllll}\text { Self-rated health (range } 0 \sim 100), & 70 \pm 18 & 66 \pm 18 & 67 \pm 19 & 0.283^{\dagger}\end{array}$

Mean \pm SD

Chi-square test, ${ }^{*}$ Fisher's exact test; ${ }^{\dagger}$ One-way ANOVA.Bonferroni method for post hoc test.

(a) Normal weight; (b) Overweight; (c) Obesity. P-values for comparisons across the three groups $[a, b$, and c]. Significant differences between normal weight and obesity [a and c]; overweight and obesity [b and $\mathrm{c}]$.

Abbreviations: ADLs: Activities of Daily Living; HRQoL: Health-Related Quality of Life; PADL: Personal Activities of Daily Living; IADL: Instrumental Activities of Daily Living; AT: Assistive Technology; IAM: Instrumental Activity Measure; SD: Standard Deviation. 
Table 2. Associations of overweight/obesity with increased difficulty in IADL (ordinal logistic regression) and with co-morbidity (binary logistic regression) in 85-year-old people.

\begin{tabular}{|c|c|c|c|c|}
\hline & \multirow{2}{*}{\multicolumn{2}{|c|}{$\begin{array}{c}\text { Overweight }(\mathrm{n}=156) * \\
\text { OR }(95 \% \mathrm{CI})\end{array}$}} & \multirow{2}{*}{\multicolumn{2}{|c|}{$\begin{array}{c}\text { Obesity }(\mathrm{n}=58)^{*} \\
\text { OR }(95 \% \mathrm{CI})\end{array}$}} \\
\hline & & & & \\
\hline & Crude & Adjusted $^{\dagger}$ & Crude & Adjusted $^{\dagger}$ \\
\hline Mobility outdoors & $1.4(0.9-2.3)$ & $1.2(0.8-2.1)$ & $2.6(1.3-2.7)$ & $2.1(1.1-4)$ \\
\hline Public transportation & $1.1(0.6-1.7)$ & $0.8(0.5-1.4)$ & $3.1(1.7-5.8)$ & $1.9(0.9-3.9)$ \\
\hline Small scale shopping & $1.8(1-3.1)$ & $1.5(0.8-2.6)$ & $2.4(1.2-4.8)$ & $1.5(0.7-3.2)$ \\
\hline Large scale shopping & $1.4(0.9-2.3)$ & $1(0.6-1.7)$ & $2.3(1.3-4.3)$ & $1.1(0.6-2.3)$ \\
\hline Cleaning & $1.4(0.9-2.2)$ & $1.2(0.8-2)$ & $3(1.7-5.4)$ & $2.2(1.2-4.2)$ \\
\hline Washing & $1.8(1.1-2.9)$ & $1.4(0.8-2.5)$ & $2.3(1.2-4.2)$ & $1.7(0.9-3.5)$ \\
\hline \multicolumn{5}{|l|}{ Co-morbidity } \\
\hline Hypertension & $1.2(0.7-1.9)$ & $1.1(0.7-1.9)$ & $1.9(1-3.7)$ & $1.6(0.8-3.2)$ \\
\hline Urinary incontinence & $1.4(0.8-2.5)$ & $1.3(0.7-2.4)$ & $3(1.5-5.8)$ & $2.2(1.1-4.7)$ \\
\hline Diabetes & $1(0.5-1.8)$ & $0.9(0.5-1.9)$ & $2.6(1.2-5.4)$ & $2.8(1.3-6.4)$ \\
\hline Chronic heart failure & $1.2(0.6-2.3)$ & $1.2(0.6-2.5)$ & $3.4(1.6-7.2)$ & $4(1.7-9.3)$ \\
\hline Multi-morbidity ( $\geq 2$ & $1.2(0.7-2)$ & $1.1(0.6-1.9)$ & $3.6(1.4-9.2)$ & $3(1.2-8)$ \\
\hline
\end{tabular}

* Reference variable: normal weight group $n=119$

${ }^{\dagger}$ Adjusted in ordinal and logistic regression analysis for gender, co-residence, type of housing, education level, and socio-economical status.

${ }^{\ddagger}$ A four-level ordinal scale (none, little, great, and impossible).

Abbreviations: IADL: Instrumental Activities of Daily Living; OR: Odds Ratio; CI: Confidence Interval. 
Table 3. Health service consumption in 2007 for 85-year-old people: normal weight, overweight, and obesity.

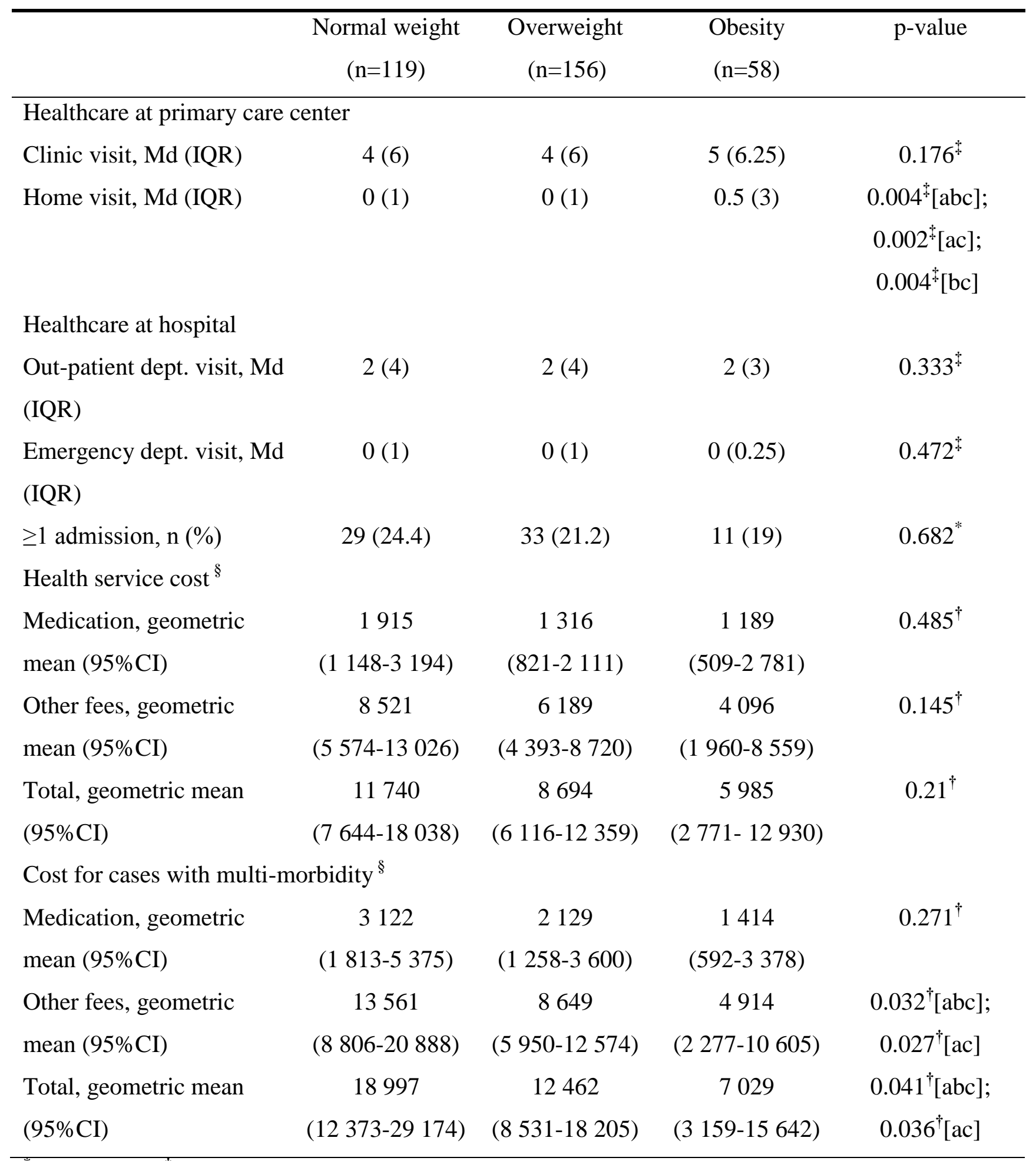

*Chi-square; One-way ANOVA. and post hoc test (Bonferroni method) after logtransformations. ${ }^{\dagger}$ Kruskal-Wallis Test. and reduced p-value $<0.017$ used for post hoc test (Mann-Whitney U test with Bonferroni method); ${ }^{\S}$ Cost: unit Swedish Crown; 
(a) Normal weight; (b) overweight; (c) obesity. P-values for comparisons across the three groups. Significant differences between normal weight and obesity [a and c]; overweight and obesity [b and c].

Abbreviations: Md: Median; IQR: Interquartile Range; CI: Confidence Interval. 
Figure 1: Flow chart of the study process.

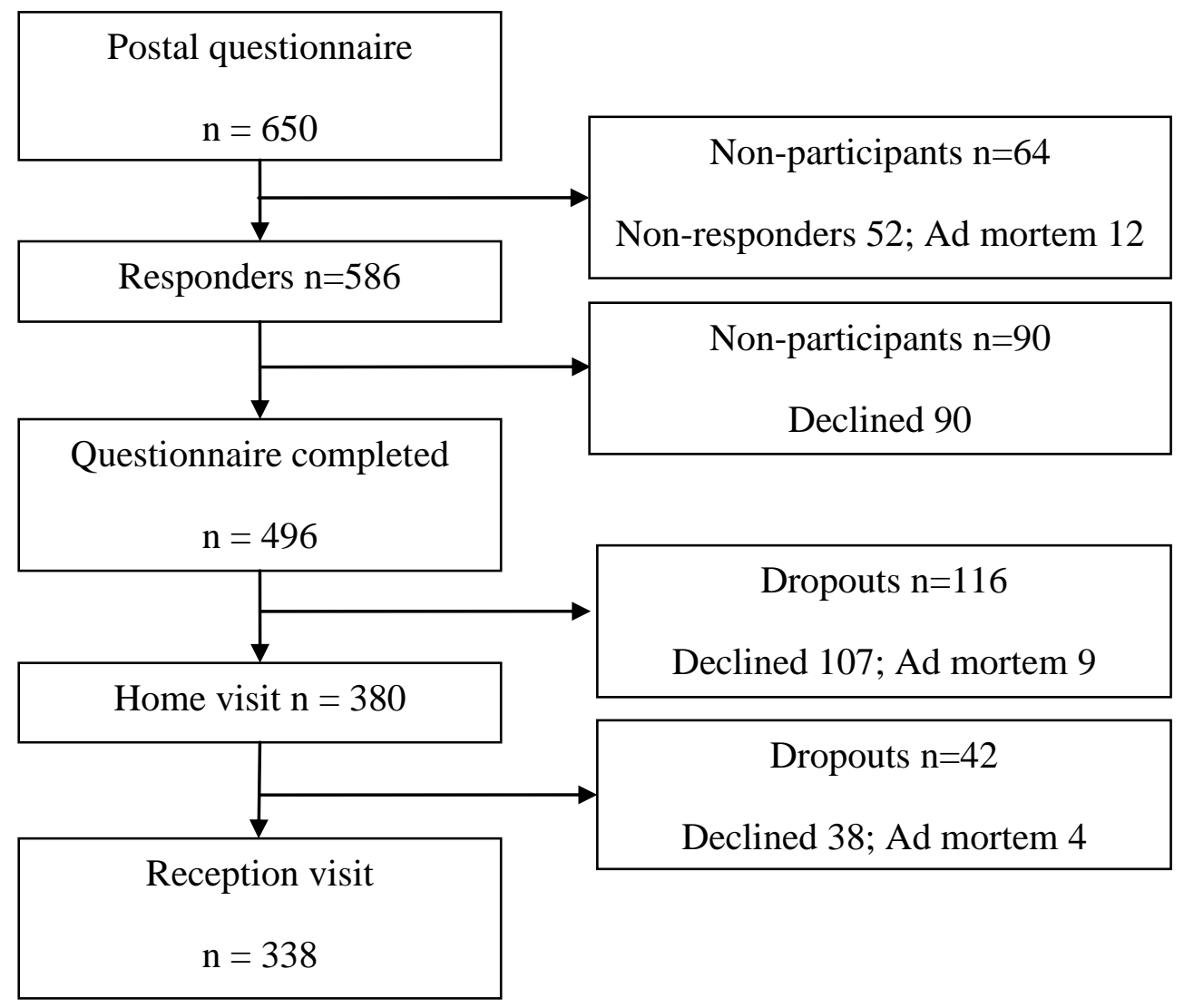




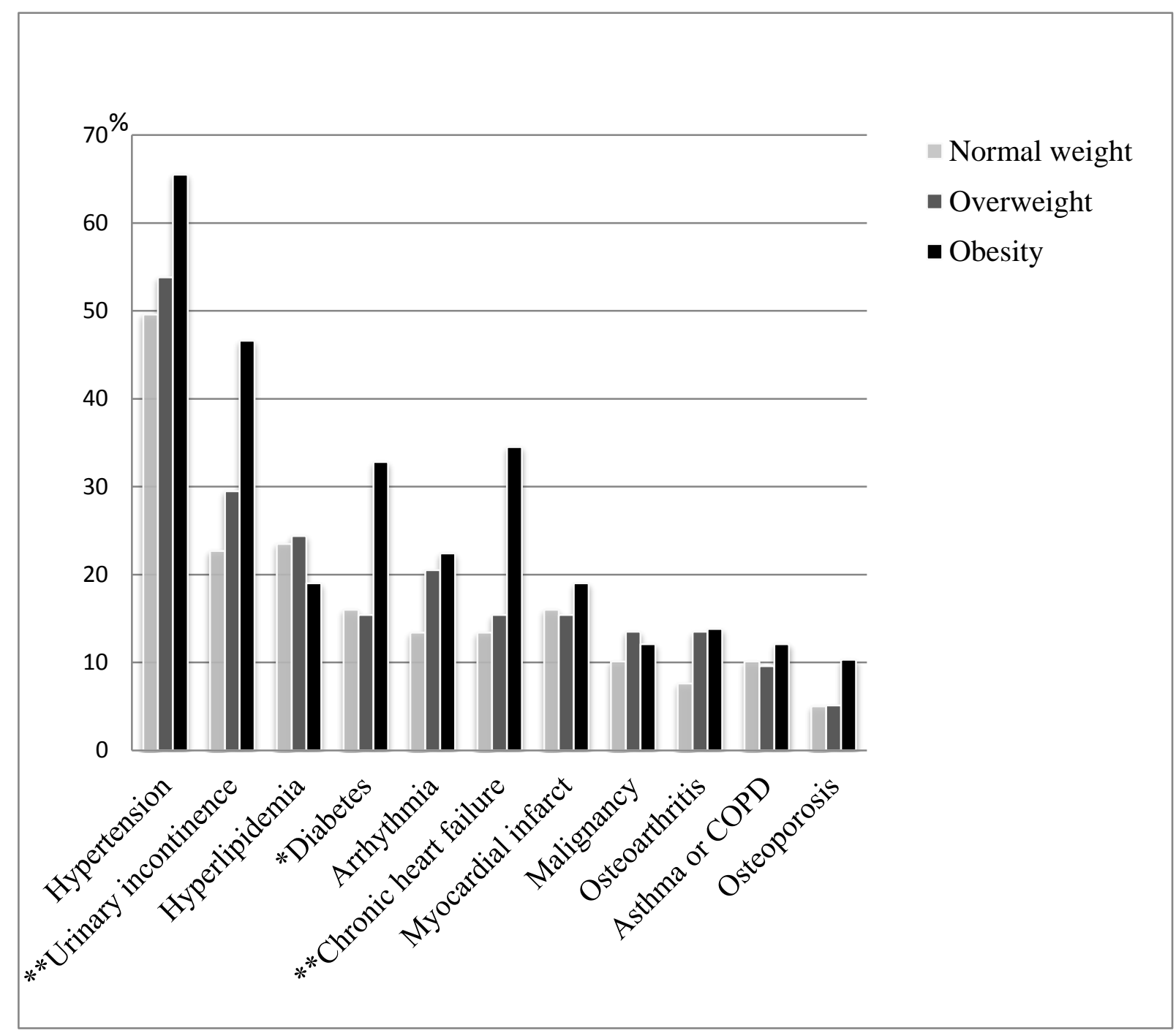

Figure 2. Morbidity in 85-year-old people with normal weight, overweight, and obesity.

COPD: Chronic Obstructive Pulmonary Disease

${ }^{*} \mathrm{P}<0.05 .{ }^{* *} \mathrm{P}<0.01$ 